\title{
EVALUATION OF UPPER-LIMB FUNCTION IN PATIENTS WITH OBSTETRIC PALSY AFTER MODIFIED SEVER-L'EPISCOPO PROCEDURE
}

José Roberval de Luna Cabral ${ }^{1}$, Bruno Eiras Crepaldi ${ }^{2}$, Marina Tommasini Carrara de Sambuy $^{3}$, Antonio Carlos da Costa ${ }^{4}$, Yussef Ali Abdouni ${ }^{5}$, Ivan Chakkour ${ }^{6}$

\section{ABSTRACT}

Objective: To evaluate upper-limb function by means of the Mallet score, in patients with medial rotation contracture of the shoulder who underwent the modified Sever-L'Episcopo procedure, and to correlate evolution with age and length of postoperative follow-up. Methods: Sixteen patients were assessed by comparing the pre and postoperative Mallet scores and correlating the differences between these scores with age at the time of surgery and length of follow-up. Results: A statistically significant improvement in the postoperative Mallet score was observed. The correlations of the differences in scores with age and length of follow-up were not statistically significant. Conclusion: The modified Sever-L'Episcopo procedure led to improved upper-limb function according to the Mallet score. Limb function did not present correlations with age or length of follow-up.

Keywords - Obstetric Palsy; Shoulder; Brachial Plexus

\section{INTRODUCTION}

Obstetric paralysis of the brachial plexus results from the traction exerted on the brachial plexus during childbirth delivery maneuvers, generally when shoulder dystocia occurs ${ }^{(1)}$. The risk factors for this are maternal diabetes mellitus, fetal macrosomia, forceps delivery and pelvic delivery. It manifests as flaccid paralysis, with either partial or complete impairment, depending on the number of roots involved. It affects 0.5 to 3 live births per 1000 in industrialized countries ${ }^{(1)}$.

The majority of the patients with obstetric paralysis of the brachial plexus present spontaneous recovery during the first months of life, without showing sequelae ${ }^{(2-4)}$. However, in some situations, muscle imbalance is seen, caused by absence of abduction and lateral rotation, and with time, this may evolve with shoulder contracture in medial rotation ${ }^{(5)}$. This condition gives rise to limitations relating to activities of daily living. In a chronic manner, it may evolve to subluxation of the shoulder and consequent deformity of the humeral head and glenoid cavity ${ }^{(6,7)}$. A series of surgical procedures have been proposed over the course of medical history, to improve function and avoid evolution to bone deformity, although it has been recognized that this is a very difficult situation to treat ${ }^{(8)}$.

In 1916 , Sever ${ }^{(9)}$ proposed releasing the subscapularis and pectoralis major muscles in order to correct the shoulder contracture in adduction and medial rotation, but without dealing with the anterior capsule of the shoulder. In 1939, L'Episcopo ${ }^{(10)}$ added to Sever's procedure, by transferring the teres major muscle to the lateral rotator, in order to improve muscle balance and function. In 1947, Zachary ${ }^{(11)}$ added to the

1 - Attending Physician in the Hand Surgery and Microsurgery Group, Irmandade da Santa Casa de Misericórdia de São Paulo, São Paulo, SP, Brazil.

2 - Resident Physician in the Orthopedics and Traumatology Clinic, Irmandade da Santa Casa de Misericórdia de São Paulo, São Paulo, SP, Brazil.

3 - Resident Physician in the Orthopedics and Traumatology Clinic, Irmandade da Santa Casa de Misericórdia de São Paulo, São Paulo, SP, Brazil.

4 - PhD. Head of the Hand Surgery and Microsurgery Group, Irmandade da Santa Casa de Misericórdia de São Paulo, São Paulo, SP, Brazil.

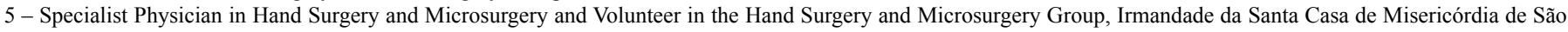
Paulo, São Paulo, SP, Brazil.

6 - PhD. Senior Consultant in the Hand Surgery and Microsurgery Group, Irmandade da Santa Casa de Misericórdia de São Paulo, São Paulo, SP, Brazil.

Work performed in the Hand Surgery and Microsurgery Group, Department of Orthopedics and Traumatology, Irmandade da Santa Casa de Misericórdia de São Paulo. Correspondence: Bruno Eiras Crepaldi, Rua Pedro Doll 531, ap. 81, Santana, 02404-001 São Paulo, SP. E-mail: brunoecrepaldi@yahoo.com.br Work received for publication: June 15, 2011; accepted for publication: October 4, 2011.

The authors declare that there was no conflict of interest in conducting this work 
surgical procedure of L'Episcopo, by transferring the latissimus dorsi muscle, in the belief that the strength of the teres major muscle alone would be insufficient to provide lateral rotation for the limb. However, it has been observed that these procedures may lead to residual limitation, particularly with regard to medial rotation, which may cause some difficulty in activities of daily living ${ }^{(12)}$.

\section{OBJECTIVE}

The objective of this study was to assess upper-limb function using the Mallet score, in patients with sequelae from obstetric paralysis of the brachial plexus, after surgical correction by means of the modified Sever-L'Episcopo technique. We also aimed to correlate age at the time of the procedure and length of postoperative follow-up with the evolution of limb function.

\section{SAMPLE AND METHOD}

A prospective study was conducted on a series of 37 patients with sequelae of obstetric paralysis of the brachial plexus and limitation of lateral rotation and abduction of the shoulder, who underwent the modified Sever-L'Episcopo surgical procedure at Santa Casa de Misericórdia de São Paulo, between January 2000 and December 2008.

The following were taken to be exclusion criteria: patients over the age of 18 years, previous osteotomy or associated procedure, use of botulinum toxin, unavailability of preoperative Mallet score and presence of glenohumeral joint abnormalities seen on preoperative simple radiographs. In the end, there were only 16 patients.

Among these 16 patients, eight were male and eight were female. Their ages ranged from three to 16 years, with a mean of 10 years and seven months. Twelve patients $(75.0 \%)$ presented the lesion on the right side and four on the left side $(25.0 \%)$. Four patients $(25.0 \%)$ presented lesions of the C5 and C6 roots; six (37.5\%), of C5, C6 and C7; and six (37.5\%), complete rupture of the plexus (Figure 1).

After assessment using the Mallet score (Figure 2), the patients underwent the modified Sever-L'Episcopo surgical procedure.

After a mean postoperative follow-up of 58 months and 15 days (range: 12 to 120 months), the patients were reassessed according to the Mallet score.



Figure 1 - Patient distribution according to the anatomical classification of the lesions.

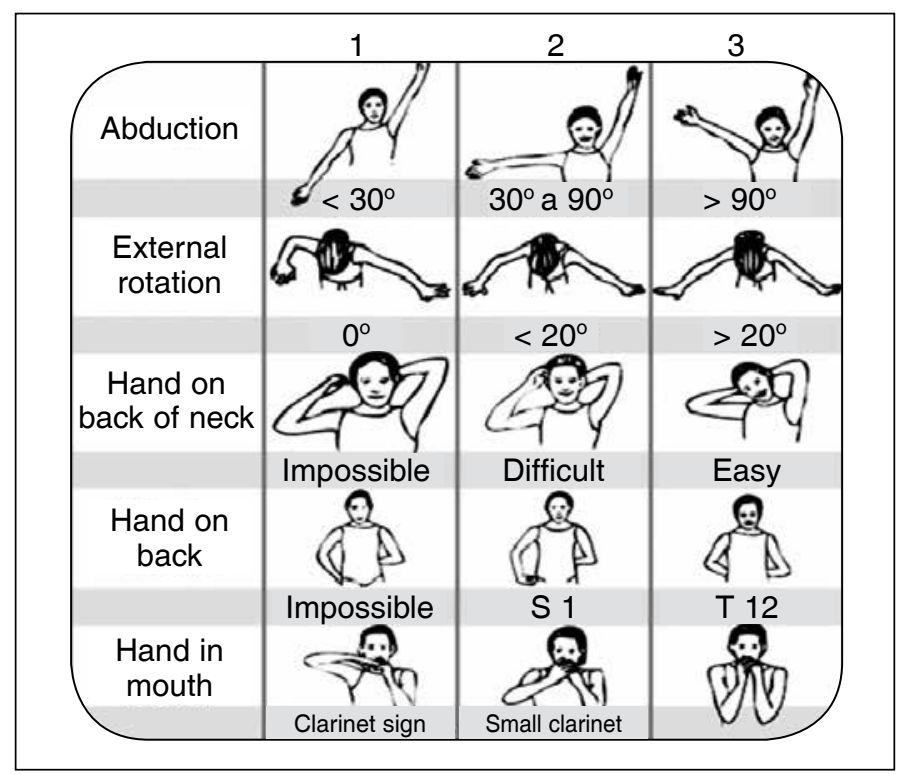

Figure 2 - Mallet score showing the evaluation stages and scoring according to the results obtained.

For the statistical analyses, we used the Epi-Info (TM) software (Centers for Disease Control and Prevention, CDC), version 3.3.2; and the NCSS/PASS 2000 software, Dawson edition. We compared the pre and postoperative Mallet scores separately and also the sum of the score items, and we correlated the difference between these pre and postoperative values in relation to age at the time of the surgery and the length of follow-up.

To investigate the association between the qualitative variables, we constructed contingency tables and used the chi-square test. For the quantitative variables, we used ANOVA. When the Bartlett test rejected homogeneity of variance $(p<0.05)$, ANOVA was discarded and we used the Kruskal-Wallis test alone. To compare quantitative data on a single individual, we used the sign test and the Wilcoxon test. We took the results to present statistical significance when $p<0.05$. 


\section{RESULTS}

The results obtained from the Mallet score before and after the operation are reported in Table 1.

In relation to abduction, four patients $(25.0 \%) \mathrm{im}-$ proved, $11(68.8 \%)$ kept the same score and one $(6.3 \%)$ worsened. Regarding lateral rotation, seven (43.8\%) improved, eight (50.0\%) kept the same score and one $(6.3 \%)$ worsened. Regarding the item "hand on the back of the neck", nine (56.3\%) improved, five (31.3\%) kept the same score and two (12.5\%) worsened. Regarding the item "hand on the back", four (25.0\%) improved, 10 $(62.5 \%)$ kept the same score and two (12.5\%) worsened. Regarding the item "hand in mouth", $10(62.5 \%)$ improved, six (37.5\%) kept the same score and none worsened.

In the statistical analysis on the Mallet score variables using the chi-square test, the scores were not validated. Correlation of the difference between the pre and postoperative summed Mallet scores with the length of follow-up until the reevaluation did not show any statistically significant difference (ANOVA, $p=$ 0.1163; Kruskal-Wallis, $p=0.1964$ ). Correlation of the difference between the pre and postoperative summed Mallet scores with the age at the time of the surgery did not show any statistically significant difference (ANOVA, $p=0.8927$; Kruskal-Wallis, $p=0.7312$ ).

Comparison between the summed pre and postoperative scores (Table 2 ) showed a statistically significant improvement (sign test, $p=0.0351$; Wilcoxon, $p=0.0043$ ). Analysis on the boxplot graphs (Figure 3 ) showed that there was an overall improvement in the scores, which were within the central part of the graph before the operation and moved to the upper part after the surgical procedures.
Table 2 - Descriptive statistics on the sums of the items in the pre and postoperative Mallet scores.

\begin{tabular}{c|c|c}
\hline Mallet score & Mean & Standard deviation \\
\hline Preoperative sum & 8.12 & 1.78 \\
\hline Postoperative sum & 10.5 & 1.89 \\
\hline Difference between sums & 2.37 & \\
\hline
\end{tabular}

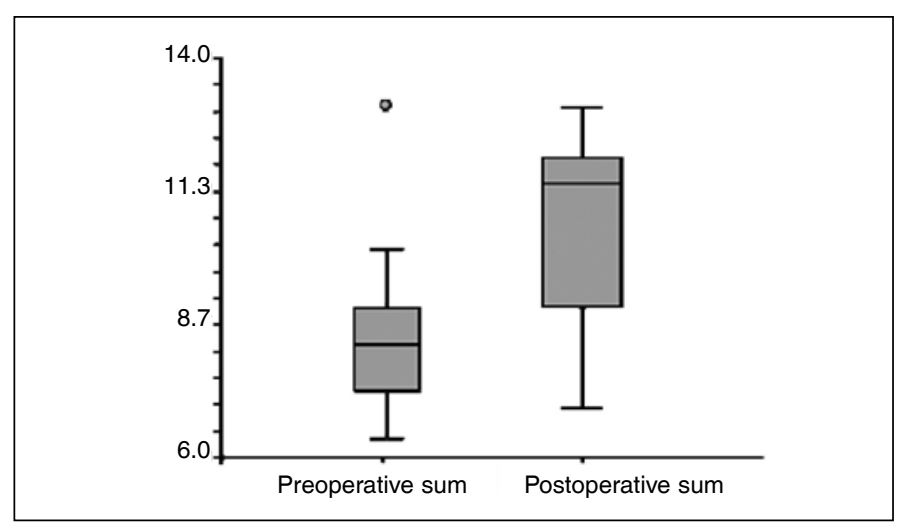

Figura 3 - Boxplot showing pre and postoperative sums in quartiles.

\section{DISCUSSION}

Shoulder muscle balance is fundamental for maintaining upper-limb form and function in patients with obstetric paralysis of the brachial plexus. Thus, loss of lateral rotation may lead to functional and esthetic abnormalities ${ }^{(13)}$. The modified Sever-L'Episcopo procedure has the aim of dynamically restoring the lateral rotation of the shoulder ${ }^{(10,11)}$.

We used the Mallet score in our study because it showed good to excellent interobserver reproducibility in previous studies ${ }^{(14)}$, thus showing that it would be a reliable instrument for the present study.

During the recent postoperative period, despite the improvement in lateral rotation, we had the impression that the patients presented difficulty in

Table 1 - Anatomical classification of the lesions and pre and postoperative Mallet scores for all the patients.

\begin{tabular}{c|c|c|c|c|c|c|c|c|c|c|c|c|c|c|c|c}
\hline & $\begin{array}{c}\text { Anatomical } \\
\text { classification }\end{array}$ & $\begin{array}{c}\text { ABD } \\
\text { pre }\end{array}$ & $\begin{array}{c}\text { LR } \\
\text { pre }\end{array}$ & $\begin{array}{c}\text { HBN } \\
\text { pre }\end{array}$ & HB pre & $\begin{array}{c}\text { HM } \\
\text { pre }\end{array}$ & $\begin{array}{c}\text { Sum } \\
\text { pre }\end{array}$ & $\begin{array}{c}\text { ABD } \\
\text { post }\end{array}$ & $\begin{array}{c}\text { LR } \\
\text { post }\end{array}$ & $\begin{array}{c}\text { HBN } \\
\text { post }\end{array}$ & $\begin{array}{c}\text { HB } \\
\text { post }\end{array}$ & $\begin{array}{c}\text { HM } \\
\text { post }\end{array}$ & $\begin{array}{c}\text { Sum } \\
\text { post }\end{array}$ & $\begin{array}{c}\text { Post-pre } \\
\text { difference }\end{array}$ & $\begin{array}{c}\text { Age } \\
\text { fongth of } \\
\text { follow-up }\end{array}$ \\
\hline 1 & Total & 2 & 1 & 2 & 1 & 1 & 7 & 2 & 1 & 3 & 1 & 2 & 9 & 2 & 12 & 120 \\
\hline 2 & Erb 5-6 & 3 & 1 & 3 & 3 & 3 & 13 & 3 & 1 & 2 & 3 & 3 & 12 & -1 & 12 & 108 \\
\hline 3 & Total & 2 & 1 & 2 & 1 & 2 & 8 & 2 & 1 & 2 & 1 & 3 & 9 & 1 & 11 & 24 \\
\hline 4 & Erb 5-6-7 & 2 & 1 & 2 & 1 & 2 & 8 & 2 & 2 & 3 & 1 & 3 & 11 & 3 & 16 & 72 \\
\hline 5 & Erb 5-6-7 & 2 & 2 & 2 & 2 & 2 & 10 & 2 & 2 & 2 & 1 & 3 & 10 & 0 & 11 & 96 \\
\hline 6 & Erb 5-6 & 2 & 1 & 3 & 1 & 2 & 9 & 2 & 1 & 3 & 3 & 3 & 12 & 3 & 3 & 12 \\
\hline 7 & Total & 2 & 1 & 1 & 2 & 1 & 7 & 2 & 2 & 2 & 1 & 1 & 8 & 1 & 15 & 36 \\
\hline 8 & Erb 5-6 & 2 & 1 & 1 & 1 & 1 & 6 & 3 & 3 & 3 & 1 & 2 & 12 & 6 & 9 & 48 \\
\hline 9 & Erb 5-6-7 & 3 & 2 & 1 & 1 & 1 & 8 & 3 & 2 & 3 & 1 & 3 & 12 & 4 & 8 & 60 \\
\hline 10 & Erb 5-6-7 & 2 & 1 & 2 & 1 & 2 & 8 & 3 & 2 & 3 & 2 & 2 & 12 & 4 & 10 & 24 \\
\hline 11 & Total & 2 & 1 & 2 & 1 & 2 & 8 & 2 & 3 & 2 & 2 & 3 & 12 & 4 & 14 & 36 \\
\hline 12 & Erb 5-6-7 & 3 & 1 & 3 & 1 & 2 & 10 & 2 & 1 & 2 & 2 & 2 & 9 & -1 & 12 & 72 \\
\hline 13 & Total & 2 & 3 & 1 & 1 & 1 & 8 & 2 & 2 & 1 & 1 & 1 & 7 & -1 & 12 & 72 \\
\hline 14 & Total & 2 & 1 & 1 & 1 & 1 & 6 & 3 & 2 & 3 & 1 & 3 & 12 & 6 & 11 & 60 \\
\hline 15 & Erb 5-6-7 & 3 & 1 & 1 & 2 & 1 & 8 & 3 & 2 & 3 & 2 & 3 & 13 & 5 & 9 & 60 \\
\hline 16 & Erb 5-6 & 2 & 1 & 1 & 1 & 1 & 6 & 3 & 1 & 2 & 1 & 1 & 8 & 2 & 4 & 36 \\
\hline
\end{tabular}


performing activities that required medial rotation of the shoulder, such as buttoning up shirts, and this was also observed by Terzis and Kokkalis ${ }^{(15)}$. However, in our series, only two patients presented worsening of the function of placing their hand on their back. Thus, we raised the hypothesis that adaptation may occur with the passage of time.

In the comparative statistical analysis on the variables of the Mallet score, the chi-square test results were not validated because the number of cases was less than five.

In analyzing the other variables separately, we observed improvements in all of them, and especially in the items of "hand on back of neck" and "hand in mouth", in which most of the patients achieved an increase of at least one level in the Mallet score.

Age at the time of the surgery may have a relationship with postoperative evolution, which would explain the worsening of the summed Mallet score items that was observed in three patients who were operated at ages above the average for our study. According to Terzis and Kokkalis ${ }^{(15)}$, children who underwent muscle-tendon transfers presented better evolution when operated before reaching the age of four years. However, in our study, the age at which the procedure was performed did not have any statistically significant relationship with the functional result, as also shown by Giostri et $a l^{(16)}$. It should be born in mind that tendon transfer is only indicated when there are no irregularities in the humeral head.
Another factor to be taken into consideration is the long period that elapsed before the patients' postoperative assessment, which may show that these patients suffered a gradual worsening after the surgical procedures. Cohen et $a l^{(17)}$ reported that after a mean period of 10 years, the summed Mallet score presented a mean decrease of approximately two points. In our study, with a mean follow-up of approximately five years, there was no statistically significant difference between the length of follow-up and the difference in the sum of the items from before to after the operation.

Although qualitative data are used in the Mallet score, we summed the items in order to quantitatively compare the pre and postoperative scores, as also done by other authors ${ }^{(15,17)}$. In this manner, an improvement in the sum of the Mallet score items was observed, which demonstrated the benefit of the Sever-L'Episcopo technique. These results are concordant with the results from other studies in the literature $^{(3,5,8,13,18)}$ and thus validate this procedure as a tool for treating loss of lateral rotation in patients with obstetric paralysis of the brachial plexus.

\section{CONCLUSION}

The modified Sever-L'Episcopo surgical procedure provided an improvement in upper-limb function, as shown by the Mallet score, and age at the time of the surgery and length of follow-up did not show any relationship with functional evolution.

\section{REFERÊNCIAS}

1. Levine MG, Holroyde J, Woods JR Jr, Siddiqi TA, Scott M, Miodovnik M. Birth trauma: incidence and predisposing factors. Obstet Gynecol. 1984;63(6):792-5.

2. Boome RS, Kaye JC. Obstetric traction injuries of the brachial plexus. Natural history, indications for surgical repair and results. J Bone Joint Surg Br. 1988;70(4):571-6.

3. Greenwald AG, Schute PC, Shiveley JL. Brachial plexus birth palsy: a 10-year report on the incidence and prognosis. J Pediatr Orthop. 1984;4(6):689-92.

4. Jackson ST, Hoffer MM, Parrish N. Brachial-plexus palsy in the newborn. J Bone Joint Surg Am. 1988;70(8):1217-20.

5. Waters PM, Bae DS. Effect of tendon transfers and extra-articular soft-tissue balancing on glenohumeral development in brachial plexus birth palsy. J Bone Joint Surg Am. 2005;87(2):320-5.

6. Dunkerton MC. Posterior dislocation of the shoulder associated with obstetric brachial plexus palsy. J Bone Joint Surg Br. 1989;71(5):764-6.

7. Fairbank HAT. A lecture on birth palsy: subluxation of the shoulder joint in infants and young children. Lancet. 1913;1:1217-23.

8. Narakas AO. Muscle transpositions in the shoulder and upper arm for sequelae of brachial plexus palsy. Clin Neurol Neurosurg. 1993;95(Suppl 1):S89-91.

9. Sever JW. Obstetric paralysis. Report of eleven hundred cases. JAMA. 1925;85:1862-5.

10. L'Episcopo JB. Restoration of muscle balance in the treatment of obstetrical paralysis. NY State J Med. 1939;39:357-63.
11. Zachary RB. Transplantation of teres major and latissimus dorsi for loss of external rotation at shoulder. Lancet. 1947;2(6482):757.

12. Freund RK, Terzis JK, Jordan L, Taylor G. Modified latissimus dorsi and teres major transfer for external rotation deficit of the shoulder. Orthopedics. 1986;9(4):505-6.

13. Strecker WB, McAllister JW, Manske PR, Schoenecker PL, Dailey LA. SeverL'Episcopo transfers in obstetrical palsy: a retrospective review of twenty cases. J Pediatr Orthop. 1990;10(4):442-4.

14. 1Bae DS, Waters PM, Zurakowski D. Reliability of three classification systems measuring active motion in brachial plexus birth palsy. J Bone Joint Surg Am. 2003;85(9):1733-8.

15. Terzis JK, Kokkalis ZT. Outcomes of secondary shoulder reconstruction in obstetrical brachial plexus palsy. Plast Reconstr Surg. 2008;122(6):1812-22.

16. Giostri GS, Machezini EJ, Pasin AP. Rotação interna na paralisia obstétrica: comparação dos resultados dos procedimentos de Sever-L'Episcopo e osteotomia derrotadora do úmero. Rev Bras Ortop. 1996;31(1):33-5.

17. Cohen G, Rampal V, Aubart-Cohen F, Seringe R, Wicart P. Brachial plexus birth palsy shoulder deformity treatment using subscapularis release combined to tendons transfer. Orthop Traumatol Surg Res. 2010;96(4):334-9.

18. Green WT, Tachdjian MO. Correction of residual deformity of the shoulder from obstetrical palsy. J Bone Joint Surg Am. 1963;45:1544-5. 